J. Lake Sci. ( 湖泊科学 ), 2006, 18( 1 ):29-35

http:// www. jlakes. org. E-mail: jlakes@ niglas. ac.cn

(c) 2006 by Journal of Lake Sciences

\title{
东营凹陷波动古湖相烃源岩沉积特征
}

\author{
陈中红, 查明, 金强 \\ ( 中国石油大学( 华东)地球资源与信息学院,东营 257061 )
}

摘 要: 以东营凹陷牛 38 井为例, 研究显示, 该井沙河街组沙三段烃源岩的沉积特征具有明显的波动性. 宏观上体现为, 构造因素控制湖盆的整体升降和沉积构造旋回,但季节性气候及其它因素的影响使湖盆呈现次级旋回的复合性沉积. 微 观上表现为纹层的不连续性及生物扰动构造等事件性沉积. 古湖面不同幅度的波动和变化导致相对稳定的泥岩沉积的 不稳定性, 有机质的分布也呈现较显著的非均质性. 湖泊的沉积过程影响了微量元素、有机质以及烃源物质的分布, 水体 较深、盐度较高的沙三段下部多数微量元素含量较高以及 $\mathrm{B} / \mathrm{Ca} 、 \mathrm{Sr} / \mathrm{Ba}$ 呈现高值;水体较浅、盐度较低的沙三段中部各元 素的分布较为稳定, B/Ca、 $\mathrm{Sr} / \mathrm{Ba}$ 比值及 $\mathrm{Sr}$ 的含量均显著降低. 波动性沉积导致烃源岩呈现明显的优劣性分布, 沙三段下 部中的有机质富集,为优质烃源岩;沙三段中部的有机质分布较为分散,生排烃的资源潜力有限.

关键词: 东营凹陷;古湖面;烃源岩;波动

\section{Sedimentary characteristics of the source rocks in fluctuation from lake facies-an example from the Well Niu-38 in the Dongying Depression, China}

CHEN Zhonghong, ZHA Ming \& JIN Qiang

( College of Earth Resources and Information, China University of Petroleum, Dongying 257061,P. R. China)

\begin{abstract}
The sedimentary course controls the distribution of minerals and source rocks. The characteristics of source rocks in the Member 3 of Shahejie Formation in Dongying Depression revealed the obvious fluctuation of the sedimentary course of lake. Tectonic movement controlled the rise and settle of the whole lake, and with the influence of climate and the other geological factors, the lake deposit was a result of complex sedimentary course which was a main sedimentary cycle contained many hypo-cycles. The heterogeneity and the unstable deposition in the stable deposition of source rocks were believed as a result of the lacustrine cyclothemic sedimentation and the lakelevel fluctuation. The environment of deep water-body and high salinity in the Member 3 of Shahejie Formation was characterized by high content of many trace elements and high value of $\mathrm{B} / \mathrm{Ca}, \mathrm{Sr} / \mathrm{Ba}$. The deposition in fluctuation contributed to the distribution of organic matter in different manners: organic matter was enrichment in the lower part of the Member 3 of Shahejie Formation, and it was source rocks in high quality; the organic matter was dispersed in the middle part of the Member 3 of Shahejie Formation, whose resource potential for hydrocarbon generation and expulsion was restricted.
\end{abstract}

Keywords : Dongying Depression;lake; source rocks; fluctuation

板内地壳运动控制了各凹陷的生成、演化以及含油气富集区的分布 ${ }^{[1]}$. 湖相烃源岩作为陆源碎屑沉积 的细粒部分, 形成于较为静态的沉积环境中, 因此能较好地保存了沉积物注人、沉积、埋藏、成岩等演化信 息, 并记录了构造沉降、气候变化、物源供给等各种因素引起的古湖盆平面和垂向变化. 研究成果显示, 古 气候、古温度发生不同变化的同时,古湖面、古水深等也呈现出相应波动性的特征 ${ }^{[2-4]}$.

烃源岩的波动式沉积影响了油气藏的形成与分布 ${ }^{[5,6]}$, 因此对古湖相烃源岩的波动性特征作探讨有着

* 国家“十五”重点科技攻关项目 (编号:2001BA605A-09-21) 资助. 2005-03-10 收稿; 2005-09-25 收修改稿. 陈中红, 男,1976 年生, 博士, 讲师;E-mail: hongczh@163.com. 
重要的理论及实践意义.

\section{1 地质概况}

东营凹陷是中国东部陆相箕状断陷湖盆的典型代表, 属于渤海湾盆地中的一个三级构造单元. 为古生 代古地形基础上,经复杂的构造运动而形成的中、新生代断陷一凹陷古湖盆 ${ }^{[7]}$. 该凹陷位于济阳凹陷南部, 北靠陈家庄凸起, 南临鲁西隆起, 西临青城凸起. 在其形成发展过程中经历了中生代张裂、早第三纪断陷和 晚第三纪坳陷三个阶段. 受北部边界陈南大断裂的控制, 古近系沉积了一套以泥质为主夹碳酸盐岩的烃源 岩. 在构造运动的控制下, 该段烃源岩沉积经历了盐湖相、深湖相及河流 - 三角洲相旋回式沉积过程. 沙四 段一沙二段是湖盆发育的主旋回沉积层, 其中的深湖相可划分为三个组合: 强烈断陷期深湖相泥岩组合 ( 沙三段下部顶以下)、稳定断陷期深湖相泥岩组合( 沙三段下部顶至沙三段中部)及断陷衰退期深湖相泥 岩组合( 沙三段中上部至沙三段上部 $)^{[8]}$.

\section{2 烃源岩沉积特征}

牛 38 井位于东营凹陷南部的牛庄洼陷, 距牛庄镇 $5 \mathrm{~km}$. 该井 “七五” 以来就成为国家攻关项目的重点 井, 是目前国内连续取心最长, 泥岩比例最高的井段. 研究井段 $(2770-3376 \mathrm{~m})$ 可以划分为 4 个层段: 沙三 段中上部 $(2770-2952 \mathrm{~m}$ )、沙三段中中部( $2952-3090 \mathrm{~m}$ )、沙三段中下部( $3090-3263 \mathrm{~m}$ )及沙三段下部 (3263-3376 m ). 各层段具有不同的沉积环境和岩性特征: 沙三段中上部处于氧化一还原性的前三角洲环 境中, 发育灰色及深灰色砂质泥岩, 夹有深灰色泥岩和浅灰色粉砂岩, 泥质岩中见有菱铁矿条带及碳化的植 物碎屑, 并含有少量藻类化石, 以 III 型及 II ${ }_{2}$ 型干酪根为主; 沙三段中中部处于滨浅湖的还原 - 弱还原沉积 环境,发育深灰色泥岩,并伴有深灰色泥灰岩,介形类、狍粉和藻类化石均丰富,并见有碳化的植物碎屑和黄

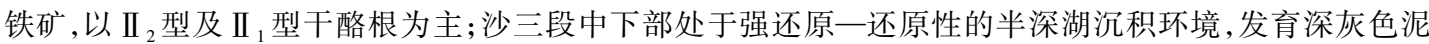
岩, 夹砂质泥岩和薄层细砂岩, 分布有多种化石及黄铁矿, 藻类化石也明显增多, 以 II ${ }_{1}$ 型及 I 型干酪根为 主; 沙三段下部( 未穿) 处于强还原性的深湖环境中, 发育深灰色、灰黑色泥岩、钙质泥岩、褐灰色油页岩, 藻 类化石富集成层, 基本为 I 型干酪根 ${ }^{[9,10]}$.

微观分析显示, 东营凹陷古近系沙河街组的深湖相泥岩主要是湖相纹层状泥页岩组成. 刘传联等人通 过对其进行高分辨率研究,认为这些湖相泥岩可进一步划分为富有机质纹层页岩、钙质纹层泥页岩、红灰条 带状粉砂质泥岩和非纹层状泥质岩, 而烃源岩均为这些纹层状泥页岩 ${ }^{[1]}$. 在微观上,泥岩虽然都呈纹层分 布,但以伸长、压扁、片状,或者藻类化石层等不同的形式存在,且具有明显不同的特征 ${ }^{[2]}$ : 富有机质纹层页 岩由有机质纹层和粘土矿物组成; 钙质纹层页岩由有机质纹层和钙质超微化石纹层组成或由有机质纹层和 含有钙质超微化石的粗粒方解石纹层组成,钙质纹层泥岩由细粒方解石纹层和含有机质的粘土矿物组成; 非纹层状泥质岩主要由块状泥岩组成. 不同性质的纹层含有不同的环境信息,富有机质纹层由生物成因所 致,在显微镜下观察,很少发现生物扰动构造, 表明环境较为闭塞, 水体出现分层, 底部水体缺氧,还原性较 强, 主要发育于沙三段下部. 碳酸盐钲质纹层及黄铁矿钻质纹层反映了化学沉积作用的存在,此类纹层反 映古湖水具有一定咸化趋势, 由于蒸发作用大于湖水补给导致, 主要出现于沙四段及沙一段,沙三段中出现 较少. 块状泥岩, 岩性均匀, 很少发现原生层理构造, 是悬浮沉积作用的产物及事件性沉积作用的结果. 其 扰动构造强烈, 显示环境极不稳定, 底层水体处于氧化环境, 多存在于沙三段中下部. 红、灰条带状粉砂质 泥岩主要发育于沙三段中上部, 以泥质纹层形式存在,其中有机质的含量与泥质纹层的发育程度有关,纹层 发育越好, 表明有机质含量越高, 随着其中有机质含量的增高, 颗粒有机质连续成片, 即演变为有机质纹层. 气候的周期性变化导致其出现季节性分层,但肉眼观察岩心, 可以发现红色层中存在生物扰动构造,显示湖 泊沉积环境较为动荡,水体分层状态并不稳定,为氧化环境. 纹层及生物扰动构造作为泥岩等细粒沉积物 中重要沉积构造, 是表征底层水分层及含氧量的重要指标, 因此上述不同纹层质泥岩的发育对于湖泊沉积 古环境的研究有着重要意义.

不同性质的源岩中有机质的赋存方式也有差异,主要有顺层富集型、分散型和局部富集型三种形 式 ${ }^{[2]}$. 富有机质纹层状泥页岩中有机质比较富集, 有机质丰度较高, 多大于 $2 \%$, 是优质烃源岩; 在沙三段 
中、下部中出现的块状泥岩及粉砂质泥岩中有机质多呈分散状态, 有机质含量低, 在 $1 \%$ 以下, 是差的烃源 岩; 钻质泥页岩中, 碳酸盐含量较高, 有机质含量多在 $1 \%$ 以上, 是较好的烃源岩.

东营凹陷古近系沙河街组烃源岩结构的多样性造成了排烃的非均一性 ${ }^{[13]}$. 从牛 38 井沙三段烃源岩 岩性看( 表 1 ), 主要为大段的纯泥岩, 并含一定的泥包砂及嵌人式夹层, 表明在稳定的泥岩沉积时期不稳定 的环境变化,有利于粗碎屑沉积物的注人. 这种泥包砂结构对油气勘探有着一定的积极意义, 超压泥岩体 周围的透镜状砂体是隐蔽油气藏的潜在目标. 由于压实不均衡及大量烃类的生成, 造成了沙河街组泥岩系 列中发育超压, 为成藏提供了动力条件. 该超压体系构成准封闭的超压封存箱型自源油气成藏动力学系 统, 同时也可以通过幕式排放为浅层的新近系、第四系及古近系的沙三段上部至东营组常压开放性它源油 气成藏动力学系统提供油源及成藏动力 ${ }^{[14]}$.

表 1 牛 38 井沙三段烃源岩岩性结构

Tab. 1 The lithologic structure of source rocks in the Member 3 of Niu-38 well

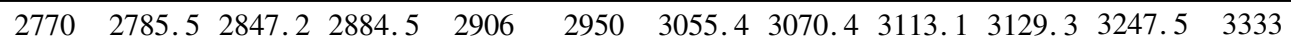

层段

$2785.5 \quad 2847.2 \quad 2884.5 \quad 2906$

2950

3055.43070 .4

113.1

$3129.3 \quad 3247.5 \quad 3333$

3367

岩性 砂岩

结构 嵌人式 纯泥岩 泥包砂 纯泥岩 泥包砂 纯泥岩

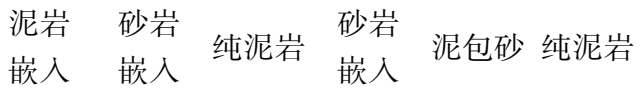

沙三段下部烃源岩沉积结构显示了十分明显的深湖相特征, 但这种深湖相泥岩又并不十分稳定, 除一 些纹层状泥岩外, 大多泥岩呈块状结构, 其间夹有一些颜色较浅的薄层状粉 - 细砂岩或泥质粉沙岩, 具断续 状水平层理、透镜状层理及波状层理, 这些微波状层理、透镜状层理的发育指示着湖底存在弱动力作用, 表 明当时湖水的分层状态并十分稳定. 同时, 在黑色泥岩中, 常夹杂有一些透镜状砂岩, 粉 - 细砂质透镜体被 泥质沉积物所包围, 以及透镜体多不连续, 呈带状, 厚度较小等现象, 也显示深湖区沉积环境的不稳定事件

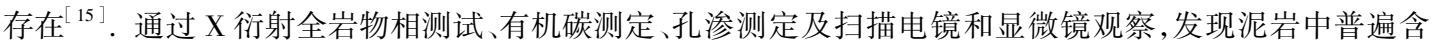
碎屑矿物, 纯泥岩并不多见 ${ }^{[16]}$.

这种相对稳定的湖控泥岩系沉积中偶尔夹杂着流控泥岩系和滑塌泥岩沉积 ${ }^{8]}$, 形成了黑页岩、钲片页 岩、钲质页岩、均匀块状泥岩与递变纹层泥岩、不均匀块状泥岩及变形泥岩形成复杂的泥岩系列, 以及包裹 着一些透镜状砂岩系列, 形成了波动式深湖相烃源岩沉积特征 ${ }^{[17]}$.

\section{3 沉积过程及控制因素}

由于水深是沉积岩中有机碳含量的重要控制因素, 随着水深加大, 利于有机碳的保存, 因此水深与有机 碳含量呈正相关关系, 湖相暗色烃源岩中有机碳的丰度变化可作为古湖平面升降变换的依据 ${ }^{[18]}$, 可指示湖 盆的旋回式沉积及古湖平面波动性变化的过程( 图 1 ).

牛 38 井自然伽马能谱曲线中的铀 $(U)$ 含量值与古水深呈良好的对应关系 ${ }^{[19]}$, 其中 $U$ 值分布范围为 $2.341-5.214 \mathrm{mg} / \mathrm{kg}$, 东营凹陷沙三段古水深为 $20-50 \mathrm{~m}^{[20]}$, 可粗略建立古水深与 $U$ 值的函数关系: $y=$ $6.9614 x+13.7033$, 其中 $y$ 为古水深, $x$ 为 $U$ 值. 根据此函数关系, 可将自然伽马能谱曲线中的铀曲线转化 为古水深曲线. 在某一段时间内, 湖平面在某一基面附近上下振动,则该基面可以看作是波动基面,在平面 图上显示为波动基线. 图 2 显示牛 38 井沙三段 $2770-3376 \mathrm{~m}$ 湖平面波动曲线, 可以看出从深到浅湖平面 波动基线总体上逐渐降低,显示湖水逐渐后退、湖平面逐渐降低的过程. 虽然湖平面波动基线变化比较平 缓,但湖平面波动曲线显示湖平面在基面附近做高频振动,这点在图 3 中更能较好地得到说明.

从宏观上看, 东营凹陷在沙三段下部沉积时, 湖盆处于稳定沉降时期, 形成深水湖相沉积. 那些对水深 适应能力较强的水生生物 (如华北介、玻璃介) 比较繁盛, 成为深湖相有机质的主要来源. 虽然有少量淡水 的注人, 但由于蒸发作用较强, 盐度较高, 湖水出现分层, 湖底呈戻氧环境, 对有机质保存和类脂组分富集非 常有利. 主要发育较强生烃能力的 I 型有机质, 烃源岩为黑色页岩、油页岩等优质烃源岩, 矿物中方解石、 黄铁矿含量较高, 分别为 $15 \%$ 和 $2 \%$, 显示沉积界面为硫化物相和强还原环境. 另一方面, 地球化学特征又 


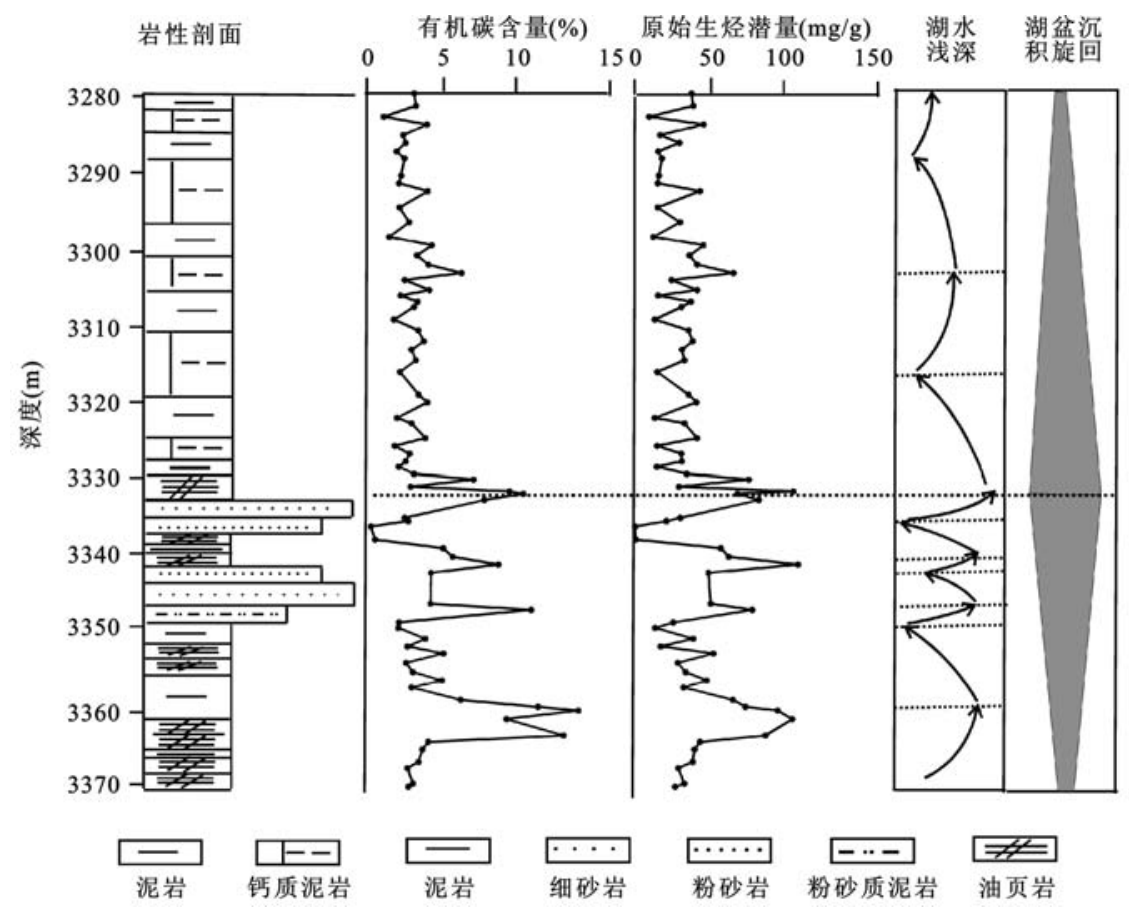

图 1 牛 38 井沙 3 下段有机碳含量及原始生烃潜量的波动性分布

Fig. 1 Fluctuation of TOC and original hydrocarbon quantity of the source rocks from Niu-38 well

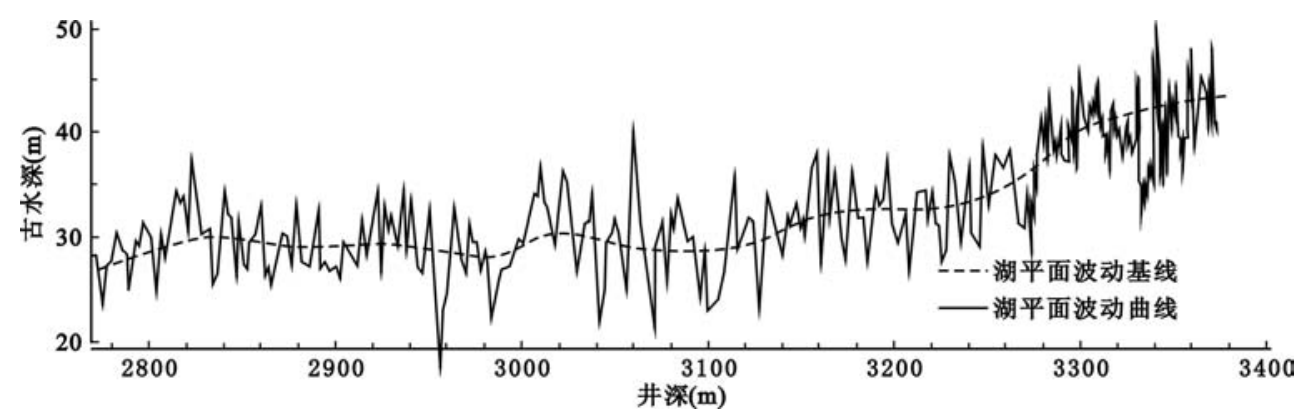

图 2 牛 38 井沙河街组古水深波动变化曲线

Fig. 2 The wave movement of lake-level at time of Shahejie Formation's deposition of Niu-38 well

显示沙三段下部的沉积环境具有较强的波动性,这从牛 38 井沙三段下部 $3350-3370 \mathrm{~m}$ 生物标志物的分布 特征可以反映( 图 4 ).

到沙三段中下部沉积时, 湖盆抬升, 湖水后退, 取样钻点演化为河流 - 三角洲沉积,并不断向湖区推进, 湖水的后退为湖盆带来陆源碎屑沉积物及具一定陆源特征的 II 型有机质, 同时也携带人一定量的氧, 破坏 了原来的还原性水体,使该时期的产烃潜能下降. 而到了沙三段中中部及上部时,湖盆抬升增强,湖面收 缩, 取样点演化为低水位的滨浅湖到三角洲沉积, 由于河水的大量注人,使该时期湖盆处于动力作用较强的 氧化状态, 而河水携带进人的 II 2 型及 III 型陆源有机质遭到氧化分解, 使该时期沉积的有机质产烃潜能急剧 下降. 沙三段中部沉积期,沉积物多为深灰色、灰色泥岩, 以块状层理为主, 矿物含量中方解石降到 $4.2 \%$ 左 右,偶尔也能见到黄铁矿. 与沙三段下部相比,水体还原性大为减弱, 厌氧菌类的分解作用也较弱,使得有 机质保存条件变差, 但由于部分藻类具有较强的抗降解能力, 因此也能发现有机质的局部富集现象. 


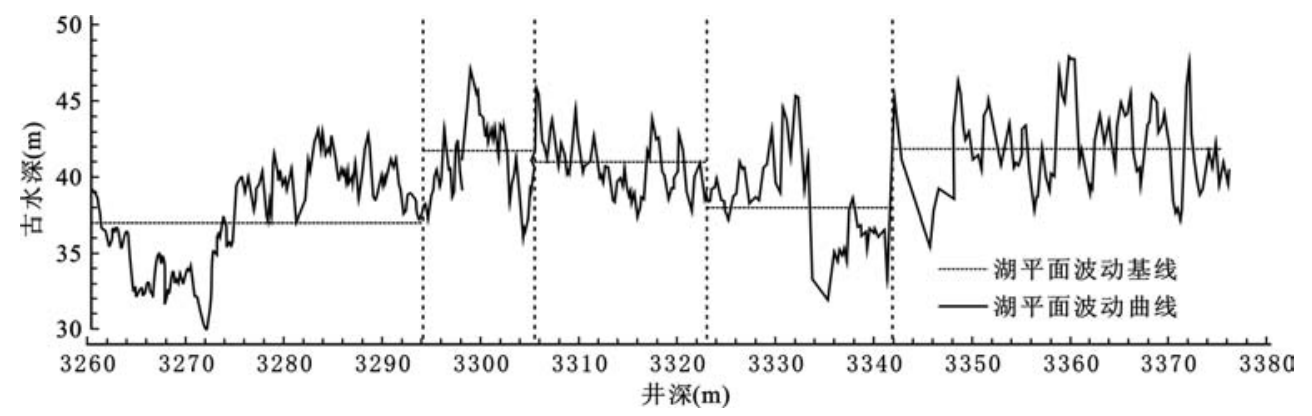

图 3 牛 38 井沙三段下部古水深波动变化曲线

Fig. 3 The wave movement of lake-level in the lower part of Shahejie Formation of Niu-38 well
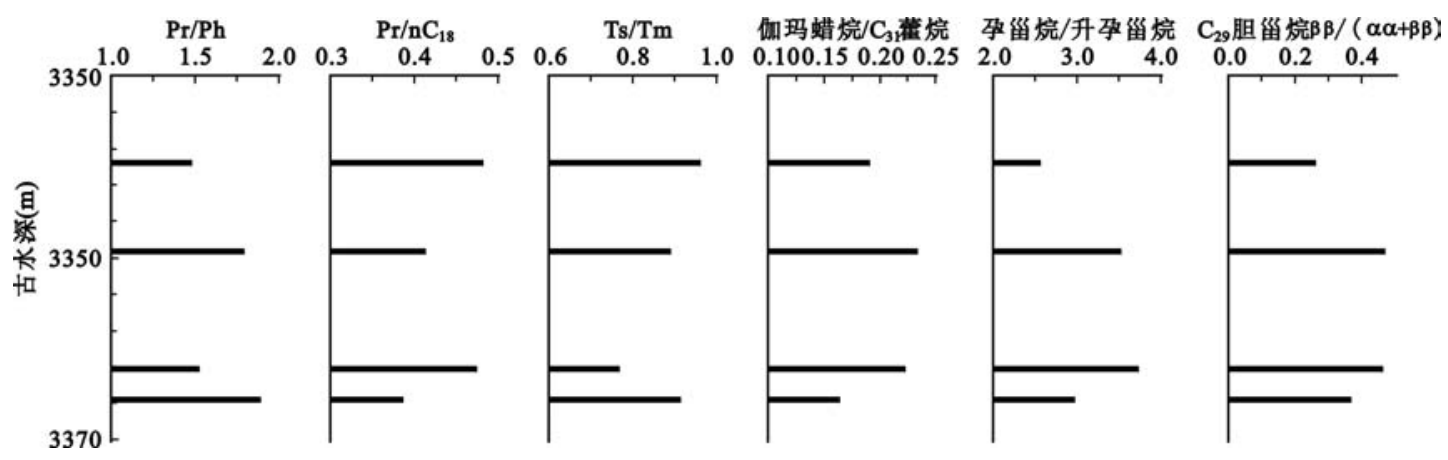

图 4 牛 38 沙河三下生物标志物分布特征 ${ }^{[9]}$

Fig. 4 The distribution of biological marker in the lower part of Shahejie Formation of Niu-38 well

\section{表 2 牛 38 井不同段烃源岩排烃结果统计}

Tab. 2 The result of hydrocarbon generation and expulsion of different members from Niu-38 well

\begin{tabular}{cccccccccccccc}
\hline \multirow{2}{*}{ 层位 } & \multicolumn{3}{c}{ 有机质含量 $(\%)$} & \multicolumn{1}{l}{ 始生烃潜量 $(\mathrm{mg} / \mathrm{g})$} & \multicolumn{3}{c}{ 排烃量 $(\mathrm{mg} / \mathrm{g})$} & \multicolumn{3}{c}{ 残烃量 $(\mathrm{mg} / \mathrm{g})$} \\
\cline { 2 - 11 } & 最大 & 最小 & 平均 & 最大 & 最小 & 平均 & 最大 & 最小 & 平均 & 最大 & 最小 & 平均 \\
\hline 沙三段中上部 & 4.81 & 0.32 & 1.09 & 50.99 & 0.68 & 4.95 & 74.31 & 6.67 & 18.93 & 0.37 & 0.07 & 2.33 \\
沙三段中中部 & 3.19 & 0.51 & 1.524 & 39.17 & 1.16 & 8.91 & 11.91 & 1.66 & 6.44 & 17.34 & 0.38 & 4.62 \\
沙三段中下部 & 6.78 & 0.46 & 2.01 & 50.18 & 0.86 & 15.71 & 4.26 & 0.78 & 2.74 & 27.31 & 0.29 & 8.25 \\
沙三段下部 & 13.75 & 0.34 & 4.00 & 143.92 & 0.65 & 37.25 & 1.20 & 0.27 & 0.70 & 72.89 & 0.39 & 23.18 \\
\hline
\end{tabular}

虽然构造因素控制湖盆的整体升降,但气候及其它因素的影响使湖盆呈现主旋回及多级次旋回的复合 性沉积, 表现为古湖水平面呈现微观上的波动变化. 人湖水流及气候的周期性变化可使湖泊的沉积过程出 现不稳定状态 ${ }^{[21-23]}$, 其最直接体现是湖盆中出现韵律层沉积. 沙三段下部中油页岩纹层状泥岩韵律层形 成于具明显分层的较深水湖区, 是湖盆内部水体的生物与化学环境对季节性气候变动的直接响应, 其中夏 季环境效应起着关键性的作用, 当时湖盆处于严重缺氧的环境,有利于造油气生物的保存,但显微生物扰动 构造以及沉积事件性现象说明, 这种严重缺氧环境有时也不十分稳定, 出现沉积纹层的不连续性和变 形 ${ }^{[24]}$. 而该井沙三段中上部的红灰韵律层的存在表明,气候变化引起的化学沉积可能是控制韵律旋回的 主因 ${ }^{[25]}$. 王慧中等 ${ }^{[25]}$ 经频谱分析等时序分析法的估算认为该红灰韵律层是受十年级与百年级主周期的控 制, 可能与太阳黑子或太阳磁场活动等周期有关.

\section{4 元素分布和影响因素}

湖盆的沉积作用也控制了其中微量元素的分布. 牛 38 井微量元素分布显示出一定波动性, 但其强烈 


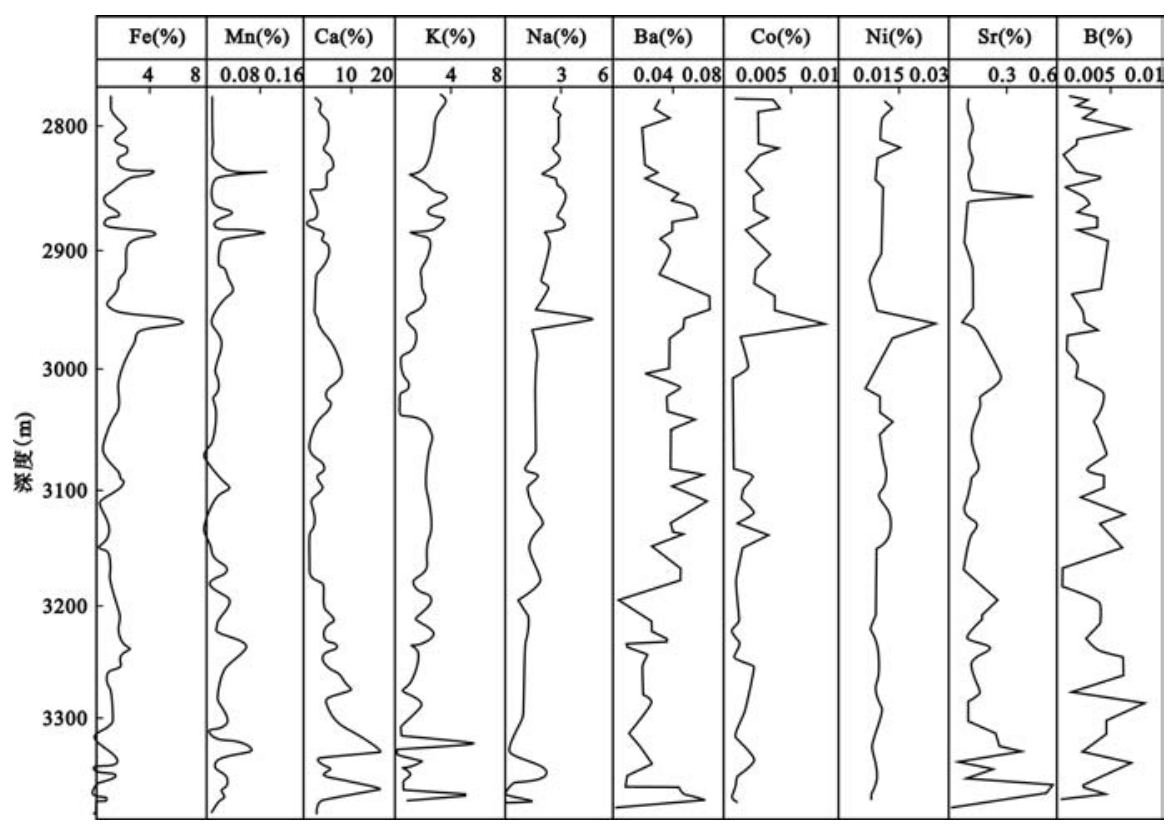

图 5 牛 38 沙河街组各矿物元素含量分布

Fig. 5 The distribution of the content of mineral element in the Member 3 of Niu-38 well

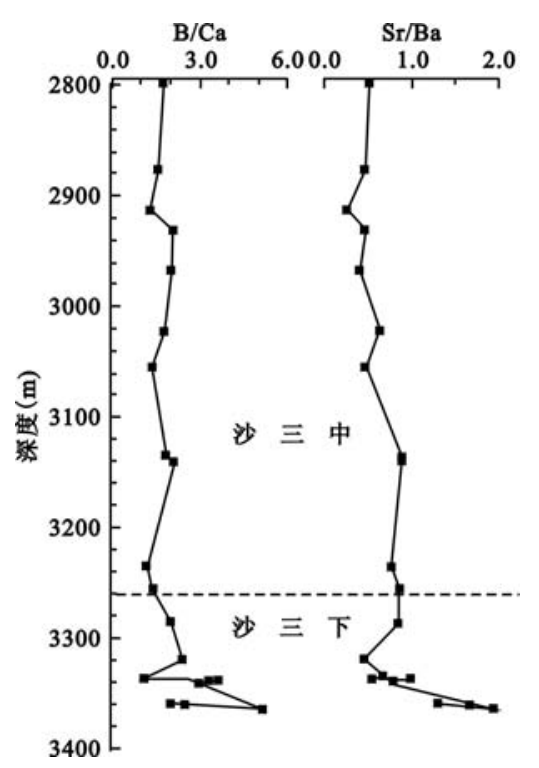

图 6 牛 38 沙河街组 $\mathrm{B} / \mathrm{Ca} 、 \mathrm{Sr} / \mathrm{Ba}$ 分布

Fig. 6 The distribution of $\mathrm{B} / \mathrm{Ca} 、 \mathrm{Sr} / \mathrm{Ba}$ in the Member 3 of Niu-38 well
程度受湖盆沉积过程控制( 图 5 ). 与上部的沙三段中部相比, 沙三 段下部多数微量元素含量较高以及 $\mathrm{B} / \mathrm{Ca} 、 \mathrm{Sr} / \mathrm{Ba}($ 图 6 ) 的高值均指 示水体较深、盐度较高的沉积环境 ${ }^{[26]}$. 沙三段中部各元素的分布 较为稳定, B/Ca、 $\mathrm{Sr} / \mathrm{Ba}$ 比值及 $\mathrm{Sr}$ 的含量均显著降低, 表明沙三段 中部水体深度变浅、盐度降低.

湖盆的波动式沉积也控制了烃源岩的非均质性分布. 沙三段 下部烃源岩明显优于沙三段中部烃源岩, 沙三段下部中有机碳含 量 $(\mathrm{TOC})$ 较高, 平均为 $4.0 \%$, 烃指数 $\left(\mathrm{S}_{1} / \mathrm{TOC} \times 100\right.$, 单位 $\left.\mathrm{mg} / \mathrm{g}\right)$ 平 均值为 $65.58 \mathrm{mg} / \mathrm{g}$, 氢指数 $\left(\mathrm{S}_{2} / \mathrm{TOC} \times 100\right.$, 单位 $\left.\mathrm{mg} / \mathrm{g}\right)$ 多在 500 $\mathrm{mg} / \mathrm{g}$ 以上, 为富氢的 I 型有机质, 单位烃源岩的生烃量、排烃量也 明显高于沙三段中部, 显示了湖盆的沉积过程对烃源岩生排烃的 优越控制影响.

\section{5 结论}

波动性是该井沙河街组沙三段烃源岩沉积的显著特征, 宏观 上,构造因素控制湖盆的整体升降和沉积构造旋回,但气候的季节 性变化及其它因素的影响使湖盆呈现次级旋回的复合性沉积, 微 观上表现为纹层的不连续性及生物扰动构造等事件性沉积特征.

湖泊的波动性沉积过程影响了微量元素、有机质以及烃源物 质的分布. 沙三段下部多数微量元素含量较高以及 $\mathrm{B} / \mathrm{Ca} 、 \mathrm{Sr} / \mathrm{Ba}$ 的 高值均指示水体较深、盐度较高的沉积环境; 沙三段中部各元素的分布较为稳定, $\mathrm{B} / \mathrm{Ca} 、 \mathrm{Sr} / \mathrm{Ba}$ 比值及 $\mathrm{Sr}$ 的 含量均显著降低. 沙三段下部中的有机质富集, 为优质烃源岩; 沙三段中部的有机质分布较为分散, 生排烃 的资源潜力有限.

致谢: 匿名审稿专家对本文进行了认真细致的修改, 并提出了许多宝贵的意见. 在此表示衰心的感谢! 


\section{6 参考文献}

[1] 张一伟. 山东西部箕状凹陷形成的探讨. 石油学报, 1983, 4( 4):19-25.

[2] 吴艳宏, 吴瑞金, 王 强等. 运城盆地 $11 \mathrm{KaBP}$ 以来气候环境变迁与湖平面波动. 海洋地质与第四纪 地质, 2001, 21( 2 ):83-86.

[3] 李志民, 吕金福, 冷雪天等. 大布苏湖全新世沉积岩芯的粒度特征与湖面波动. 东北师范大学报( 自 然科学版 ), 2000, 32( 2):118-122.

[4] 王云飞, 夏威岗, 潘红玺等. 淮河中游本世纪气候与环境波动的湖泊记录证据. 湖泊科学, 1998, 10 ( 2 ) $: 52-57$.

[ 5 ] 吕修祥, 张一伟,李德生. 从波动观点看渤海湾盆地济阳坳陷油气田分布. 石油实验地质, 1996, 18 ( 3 ): $259-266$.

[6] 刘国臣, 张一伟. 从波动观点看塔里木盆地的成藏演化史. 石油学报, 1999,20( 2):7 - 11 .

[7] 袁 静,赵澄林,张善文. 东营凹陷沙四段盐湖的深水成因模式. 沉积学报,2000,18(1):114-118.

[8] 邓洪文,钱 凯. 深湖相泥岩的成因类型和组合演化. 沉积学报, 1990,8 (3):1-20.

[9] 朱光有, 金 强. 烃源岩的非均质性研究一一东营凹陷牛 38 井为例. 石油学报, 2002,23( 5):34 - 39.

[10] 洪志华,陈致林,殷 沫等. 东营凹陷牛 38 井沙三段中下部有机质分布特征. 石油与天然气地质, 1991, 12 ( 3 ):292 - 299.

[11] 刘传联,舒小辛,刘志伟. 济阳凹陷下第三系湖相生油岩的微观特征. 沉积学报, 2001,19( 2 ): 293 -298 .

[12] 苗建宇, 祝总祺, 刘文容等. 泥质岩有机质的赋存状态及其对泥质岩封盖能力的影响. 沉积学报, 1999,17 ( 3 ): $478-481$.

[13] 陈中红, 查 明. 济阳坳陷古近系烃源岩结构及排烃的非均一性. 石油勘探与开发, 2003,30( 6 ):45 48.

[14] 陈中红, 查 明. 东营凹陷烃源岩超压体系特征及勘探意义. 大庆石油勘探与开发,2004,23( 3 ): 11 $-13$.

[15] 朱光有,金 强,周建林. 东营凹陷旋回式深湖相烃源岩研究. 地质科学, 2003,38(2):254 - 262 .

[16] 苗建宇, 祝总祺, 刘文容等. 济阳凹陷古近系一新近系泥岩孔隙结构特征. 地质论评, 2003,49( 3$): 330$ -336 .

[ 17 ] 朱光有,金 强,周建林等. 渤海湾盆地东营断陷湖盆充填模式研究. 石油实验地质, 2003,25( 2): 143 -152 .

[ 18 ] 杨明慧,夏文臣,张兵山等. 非海相盆地准层序级别的有机相变化及其地质意义. 沉积学报, 2000,18 ( 2 ):297-301.

[19] 陈中红,查 明,金 强. 铀曲线在沉积盆地古环境反演中的应用. 石油大学学报,2004,28(6):11-15.

[20] 查 明. 断陷盆地油气二次排运与聚集. 北京:地质出版社, 1997:95

[21] 王苏民.张振克. 中国湖泊沉积与环境演变演变研究的新进展. 科学通报, 1999, 44(6):579-587.

[22] 张振克,王苏民. 中国湖泊沉积记录的环境演变: 研究进展与展望. 地球科学进展, 1999,14( 4 ): 417 -422 .

[23] 刘传联, 赵泉鸿, 汪品先. 东营凹陷生油岩中介形虫氧、碳同位素的古湖泊学意义. 地球科学一一国 地质大学学报,2001,26( 5 ):441-445.

[24] 王慧中,梅洪明. 东营凹陷沙三下亚段油页岩中古湖泊学信息. 同济大学学报, 1998,26( 3):315 - 319.

[25] 王慧中,盛 蔚,舒小辛等. 东营凹陷牛 38 井沙三中上段红灰韵律层中的环境信息. 沉积学报, 1996, 14( 1 ):47 - 57 .

[26] 张永生, 杨玉卿, 漆志先等. 江汉盆地潜江凹陷古近系潜江组含盐岩系沉积特征与沉积环境. 古地理 学报, 2003, 5( 1 ):29-35. 